\title{
Deteriorating Patients and Risk Assessment among Nurses and Junior Doctors: A Review
}

\author{
Ludin, $\mathrm{SM}^{\mathrm{a}}$, Ruslan, $\mathrm{R}^{\mathrm{a}}$, Mat Nor, $\mathrm{MB}^{\mathrm{b}}$ \\ ${ }^{a}$ Critical Care Nursing Department, Kulliyyah of Nursing, International Islamic University, Malaysia \\ ${ }^{b}$ Anaesthesiology Department, Kulliyyah of Medicine, International Islamic University, Malaysia
}

\begin{abstract}
The presence of nurses and junior doctors in the ward environment are crucial, especially in detecting deteriorating patients. However, there is consistent evidence that warning signs may not always be identified or acted upon. This paper aimed to analyse the incidence of deteriorating patients, and the concept of risk assessment of these patients by nurses and junior doctors in general ward, through a review on relevant literature. An extensive literature search was conducted through online research databases, i.e. CINAHL, MEDLINE (Ovid), Science Direct and ProQuest. Professional journals were hand searched for relevant literature based on reference lists and citations made in key publications, and attempts were also made to obtain any relevant grey literature (unpublished materials). A total of eleven papers which focused on patient's assessment, response to deteriorating patients and knowledge in medication, and a guideline were reviewed. Most of the studies were carried out in the United Kingdom $(n=4)$, followed by Australia $(n=2)$, Sweden $(n=2)$, the Netherlands $(n=1)$ and Taiwan $(n=1)$. Meanwhile, among these studies, the chosen research designs include, qualitative $(n=6)$, quantitative $(n=3)$ and systematic review $(n=1)$. This review concluded that nurses and junior doctors in general ward have a lack of knowledge in risk assessment of deteriorating patients.
\end{abstract}

KEYWORDS: deteriorating patients, risk assessment, nurses, junior doctors

\section{INTRODUCTION}

Nurses and junior doctors are among the main workforces in general ward of a hospital. Their presence in the ward environment are crucial, especially in detecting deteriorating patients. Their skills and knowledge are also crucial, in determining the quality of care provided to the patients. Nowadays, patients' characteristics are changing globally. Published data shows an increasing trend of patients with complex conditions, and are more likely to be or become seriously ill during hospitalisation. ${ }^{1}$ Focusing on the delivery of care to these high risk patients has been recognised as a potential way in reducing the mortality rate. ${ }^{2}$

Therefore, early identification and effective resuscitation during hospitalisation are important in securing the patients' life and reducing admission

Corresponding author:

Dr. Salizar Mohmed Ludin

Critical Care Nursing Department,

Kulliyyah of Nursing,

International Islamic University

Malaysia, P.O.Box 141,

25710, Kuantan, Pahang, Malaysia

Tel No: 09-5707281(Off)

019-2229942(Mobile)

Email:msalizar@iium.edu.my rate to intensive care setting. ${ }^{3} \mathrm{~A}$ reliable, timely and error-free care should increase survival rate of critically ill patients. Generally, during hospitalisation, nurses and junior doctors are the first responders for any incidents related to critically ill patients. Therefore, it is important to know their skills and knowledge in managing such patients.

The aim of this review was to analyse the incidence of deteriorating patients, and the concept of risk assessment and response to these patients in general ward, by nurses and junior doctors. In addition, this current review also aimed to identify the nurses' and junior doctors' knowledge in emergency pharmacotherapy.

\section{MATERIALS AND METHODS \\ Search strategy and data sources}

The literature review was conducted as a systematic process, which began in September 2014 and completed in January 2016, allowing the identification of research published throughout the course of this study. Computer-based electronic search was implemented to access the library databases, and search all online nursing and medical journals and books published between 1998 and 2016. The year of 1998 was selected as the end parameter for older published works, as this was the year where McQuillan et al. published a seminal study that identified suboptimal patient management prior to emergency intensive care admission. $^{3}$ 
The search terms used, either separately or combined, were deteriorating patients in the general ward, acutely ill patients in general ward, early warning signs and scores, risk assessment, track and trigger systems, critical care outreach, emergency pharmacotherapy, prescribing error, and response and patient's observation. The electronic databases include CINAHL, MEDLINE (Ovid), Science Direct and ProQuest. Professional journals were hand searched for relevant literature based on the reference lists and citations made in key publications, and attempts were also made to obtain any relevant grey literature (unpublished materials).

All primary research of any designs published between 1998 and 2016, which explored the risk assessment and response to deteriorating patients in the medical ward, nurses' and junior doctors' knowledge in emergency pharmacotherapy, and critical care outreach concept were also included in the review. A total of 11 out of 36 studies were selected for a more detail review. Studies conducted in paediatric ward were excluded, as the respondents involved and the type of electronic monitoring were not comparable. Papers which were not available in English were also rejected, on the basis that translation will take up more time due to the validation process.

Inclusion criteria includes (1) Primary studies describing nursing observation on adult patients in general hospitals, (2) All research designs, (3) All studies set in general ward environment, (4) All studies evaluating nursing observation of general ward patients, which may involve the use of early warning scores and response teams, and (5) All interventions and outcomes (except those detailed in the exclusions criteria). Exclusion criteria includes (1) Studies done in the critical care, paediatric, psychiatric, and obstetric areas and wards; and the accident and emergency department, (2) Studies evaluating the effects of medical emergency teams (MET) on the patient outcomes, and (3) Editorials, commentaries and case reviews.

\section{RESULTS}

A total of eleven papers which focused on patient's assessment, response to deteriorating patients and knowledge in medication, and a guideline were reviewed. Most of the studies were carried out in the United Kingdom $(n=5)$, followed by Australia $(n=2)$, Sweden $(n=2)$, the Netherlands $(n=1)$ and Taiwan $(n=1)$. Meanwhile, among these studies, the chosen research designs include, qualitative $(n=7)$, quantitative $(n=3)$ and systematic review $(n=1)$. A summary on these studies is included in Table 1.

One study carried out in the United Kingdom focused on perceptions of ward nurses and critical care outreach staffs towards management of deteriorating patients in the acute ward. ${ }^{4} \mathrm{~A}$ qualitative design was used, with Critical Incident Technique (CIT) implemented to structure the data collection. Semi-structured interviews were conducted on fourteen participants, whom were directly involved with management of deteriorating patients. The findings of this study suggested that healthcare providers need a better understanding on the track and trigger scoring systems in identifying the deteriorating patients. Furthermore, communications among healthcare providers need to be improved. However, recall bias may present during the interview sessions since these sessions were held within two to three weeks following the occurrence of the critical incidents.

A systematic review of literature concerning the transition from students to junior doctors was conducted by a previous study. ${ }^{5}$ MEDLINE and Scopus were searched for relevant literature concerning this matter, including studies that measured one or more factors that affect the preparedness of these doctors. Twenty-six articles were identified via the search process. A total of nine papers were included in this review, with various designs and methodological qualities. Seven of the papers used survey methodology. From the review, it was found that new doctors felt inadequately prepared for practice, particularly in terms of their knowledge and skills. Six papers found deficiencies in the prescribing and practical procedures. Most studies included in the review focused on the United Kingdom context. Therefore, it may not be generalisable to other countries with different training programmes and settings.

A quasi-experimental study was performed in rural Australia which involved both pre- and postintervention assessments and observations on nurses. ${ }^{6}$ The study focused on assessing the ability of rural Australian nurse teams to manage deteriorating patients. The study found poor practices, despite satisfactory knowledge. Identification and management of patients' deterioration need to be taught in professional development programmes, by incorporating high fidelity simulation technique. A total of 44 nurses from two hospital wards were involved in the study. A formative knowledge assessment and three team-based video recorded scenarios were completed. It was concluded that repetitive simulation-based education with incorporation of high psychological fidelity techniques most likely able to overcome performance deficits identified in this study with a potential in improving their clinical competence.

Another study was conducted in a single-site 700beds general hospital located in the South of England. ${ }^{7}$ The study focused on auditing ward nursing practice in adherence to the Early Warning Score (EWS) measurement protocol in the detection and initial management of deteriorating ward patients. Factors that may have impact on the practice were also investigated. It was reported that monitoring of 
Table I: Summary of all studies

\begin{tabular}{|c|c|c|c|}
\hline$\overline{\text { Bil }}$ & Author / Year / Title & Study design & Key finding \\
\hline 1. & $\begin{array}{l}\text { Donohue \& Endacott, (2010) } \\
\text { Track, trigger and teamwork: } \\
\text { Communication of } \\
\text { deterioration in acute medical } \\
\text { and surgical wards. }\end{array}$ & $\begin{array}{l}\text { Study using Critical Incident } \\
\text { Technique }(\mathrm{CIT}) \text { with } \\
\text { retrospective semi- } \\
\text { structured interviews on the } \\
\text { nurses }(\mathrm{n}=14 \text { ) who had } \\
\text { referred a patient to the } \\
\text { outreach team. }\end{array}$ & $\begin{array}{l}\text { - Knowing the patient and identifying visual } \\
\text { trends considered as important. } \\
\text { - } \quad \text { MEWS used infrequently but tools are } \\
\text { useful for inexperienced staff. }\end{array}$ \\
\hline 2. & $\begin{array}{l}\text { Cameron, A., Millar, J., } \\
\text { Szmidt, N., Hanlon, K., \& } \\
\text { Cleland, J. } \\
\text { (2014) } \\
\text { Can new doctors be prepared } \\
\text { for practice? A review. }\end{array}$ & $\begin{array}{l}\text { This was a systematic review } \\
\text { of literatures }(n=9) \\
\text { concerning the transition } \\
\text { from student to a junior } \\
\text { doctor, published in the last } \\
10 \text { years, and that measured } \\
\text { or explored one or more }\end{array}$ & $\begin{array}{l}\text { Knowledge and skills, particularly } \\
\text { deficiencies in prescribing and practical } \\
\text { procedures, relevant in terms of } \\
\text { preparedness. Personal traits, with high } \\
\text { levels of neuroticism and low confidence } \\
\text { deemed to be important. }\end{array}$ \\
\hline
\end{tabular}

3. Cooper, S., Cant, R., Porter, J., Missen, K., Sparkes, L., McConnell-Henry, T., et al. (2013)

Managing patient deterioration: assessing teamwork and individual performance. factors affecting preparedness.

This quasi-experimental design used pre- and postintervention assessments and observation to evaluate the nurses' $(n=44)$ simulated clinical performance.

Using cardiac arrest as a surrogate marker for deterioration, patient records $(n=123)$ were retrospectively reviewed during the 12 hours prior to the cardiac arrest event. A cross-sectional study among nurses $(\mathrm{n}=305)$ was conducted in 2006 in Taiwan using a questionnaire developed from literature review and expert input, and validated by subject experts and two pilot studies.

This study is a method developing study classifying reported medication errors made by the nurses $(n=33)$.
- Despite a satisfactory knowledge base, the application of knowledge was low with notable performance deficits in these demanding and stressful situations.

- The identification and management of patient deterioration needs to be taught in professional development programmes incorporating high fidelity simulation techniques.

- The team emergency assessment tool proved to be a valid measure of team performance in patient deterioration scenarios.

- Ward nurses' monitoring of patients' observations has improved compared with earlier research, but errors in early warning scoring and non-adherence to referral protocols are still a problem.

- $\quad$ Only $3.6 \%$ of nurses considered themselves to have sufficient knowledge about high-alert medications, $84.6 \%$ hoped to gain more training, and the leading obstacle reported was insufficient knowledge (75.4\%).

- A total of 184 known administration errors were identified, including wrong drug (33.7\%) and wrong dose (32.6\%); $4.9 \%$ resulted in serious consequences.

- Six main categories of errors were identified:

1) Wrong dose,

2) Wrong drug,

3) Dose(s) missed,

4) Unauthorized or unordered drug,

5) Wrong route,

6) Drug administered despite documented allergy. 


\begin{tabular}{|c|c|c|c|}
\hline Bil & Author / Year / Title & Study design & Key finding \\
\hline 7. & $\begin{array}{l}\text { Seden, K., Kirkham, J. J., } \\
\text { Kennedy, T., Lloyd, M., } \\
\text { James, S., Mcmanus, A., et al. } \\
\text { (2013) } \\
\text { Cross-sectional study of } \\
\text { prescribing errors in patients } \\
\text { admitted to nine hospitals } \\
\text { across North West England. }\end{array}$ & $\begin{array}{l}\text { Ward-based clinical } \\
\text { pharmacists prospectively } \\
\text { documented prescribing } \\
\text { errors by junior doctor at } \\
\text { the point of clinically } \\
\text { checking admission or } \\
\text { discharge prescriptions } \\
(n=4238) \text {. }\end{array}$ & $\begin{array}{l}\text { The rate of error was not significantly } \\
\text { different between newly qualified } \\
\text { doctors compared with junior, middle } \\
\text { grade or senior doctors. } \\
\text { High rate of error from the omission of } \\
\text { medication, particularly among } \\
\text { patients admitted acutely into } \\
\text { hospital. Electronic prescribing systems } \\
\text { could potentially have prevented up to } \\
\text { a quarter of errors. }\end{array}$ \\
\hline
\end{tabular}

8. Ludikhuize, J., Smorenburg, S. Retrospective observational M., de Rooij, S. E., \& de Jonge, E.

(2012).

Identification of deteriorating patients in general ward; measurement of vital parameters and potential effectiveness of the Modified Early Warning Score (MEWS). study of medical and surgical patients $(n=204)$ from 2007 with a severe adverse event including cardiopulmonary arrest, unplanned intensive care unit (ICU) admission, emergency surgery, or unexpected death.
- $\quad$ Overall $81 \%$ of the patients had a MEWS value of 3 or more at least once during 48 hours before the event.

- $\quad$ Recordings of vital signs were mostly incomplete.

- Even when the MEWS was 3 or more, respiratory rate, diuresis, and oxygen saturation were documented in only $30 \%$ to $66 \%$ of the assessments.
9. Konrad, D., Jaderling, G., Bell, M., Graath, F., Ekbom, A., \& Martling, C.-R. (2010). Reducing in-hospital cardiac arrests and hospital mortality by introducing a medical emergency team (MET).

10. Considine, J., \& Currey, J. (2014).

Ensuring a proactive, evidence -based, patient safety approach to patient assessment.

11. National Institute for Health and Clinical Excellence (NICE) (2007).

Acute illness in adults in hospital: Recognising and responding to deterioration.
Prospective before-and-after trial of implementation of MET. The study included all adult patients $(n=73825)$; apart from cardiothoracic, admitted to the hospital were regarded as participants in the study.

A descriptive exploratory design was used and the study data were collected using a prospective point prevalence approach. A total of 178 patients were involved in the study.

Clinical guideline for recognising and responding to deterioration. The guideline was established in the United Kingdom.
- $\quad$ MET implementation was associated with a reduction in hospital mortality.

- Cardiac arrest was reducing by $26 \%$ even from a low basal incidence.

- $\quad$ The most frequently documented physiological observations were respiratory rate, oxygen saturation, heart rate and systolic blood pressure.

- $\quad$ The least frequently recorded physiological observations were temperature and conscious state.

- $\quad$ Routine measurements are accurately taken and recorded by staff that understand their clinical relevance, and by linking these observations to a graded track and trigger system, care can be escalated appropriately. 
patients by ward nurses has been improved, compared to earlier studies, but errors in EWS and no adherence to referral protocols were still found to be problematic. The data were collected using a predesigned pro forma. A retrospective review on patients' medical record was also carried out. Cardiac arrest was used as a surrogate marker for deterioration. A total of 123 patients' records were included in the study.

In 2006, a cross-sectional study was conducted in Taiwan, which focused on knowledge of emergency pharmacotherapy. ${ }^{8}$ This study used a questionnaire developed based on the literature review and experts input, and was validated by subject experts and two pilot studies. A total of 305 nurses participated in the study, which corresponded to $79.2 \%$ of response rate. A total of 184 known administration errors were identified, i.e. wrong drug (33.7\%) and wrong dose (32.6\%). A total of nine cases $(4.9 \%)$ have resulted in serious consequences. The evidence-based results strongly suggest that these nurses have insufficient knowledge on high-alert medications and could benefit from additional education, particularly associated with intravenous bolus administration of these medications. ${ }^{8}$

Another study on pharmacotherapy was conducted in Sweden. However, this study focused on the development of a taxonomy for the classification of reported medication errors, and factors contributing to these errors. ${ }^{9}$ An in-depth analysis was performed on 33 reported medication errors by the nurses. Content analysis was used for categorisation of errors and the contributing factors. From the analysis, six main categories of errors were identified, i.e. (1) wrong dose, (2) wrong drug, (3) missed dose(s), (4) unauthorised or unordered drug, (5) wrong route, and (6) drug administered despite documented allergy. In addition, lack of knowledge was found to be one of the factors contributing to medication errors. ${ }^{9}$

A cross-sectional study was done at nine hospitals in the North West of England to determine the rate of error for complete prescriptions and individually prescribed items, and to provide a better estimate on the number of patients affected by these errors. This study did not evaluate the impact of electronic prescribing on the prevalence and types of the prescribing error. However, up to a quarter of these errors could be potentially avoided through the use of electronic prescribing and medication administration systems. ${ }^{10}$ Prescribing error has been one of the main contributor to medication errors. ${ }^{11}$ The findings of the study showed that only $56.2 \%$ of the 4,238 complete prescriptions remained to be error-free. However, this study found that prescribers' experience did not impact on the overall error rate. Majority of errors considered to be potentially fatal $(n=9)$ were dosing errors $(n=8)$, which were mostly related to being overdose $(n=7)$.
An academic medical hospital in Netherlands has been chosen as the study setting to identify the usefulness of Modified Early Warning System (MEWS). This retrospective observational study was carried out in medical and surgical wards in $2007 .{ }^{12}$ All vital parameters were retrospectively calculated 48 hours prior to the event. A total of 204 patients with 2,688 deteriorating events were investigated in the study. Overall, $80 \%(n=163)$ of the patients scored three or more MEWS. However, $30 \%$ to $60 \%$ of the assessments were not completed since respiratory rate, diuresis and oxygen saturation were not documented. These researchers have pointed out that the observational design and the retrospectively calculated MEWS were the limitations of the study.

A study in Sweden was carried out with the purpose to prospectively evaluate the implementation of a rapid response team (RRT) in the form of an MET, which was responsible for cardiac arrests and hospital mortality. ${ }^{13}$ This prospective before-and-after trial of implementation of the MET was conducted at the Karolinska University Hospital, Stockholm, Sweden. All adult patients admitted to the hospitals were regarded as participants in the study. A control period of 5 years and 203,892 patients proceeded the 2-years intervention period of 73,825 patients. This study reported that implementation of MET was associated with significant improvements in both cardiac arrest rate and overall adjusted hospital mortality. Moreover, significant reductions in hospital mortality due to inoperable surgical and medical patients were also observed in the study. Comparisons of MET survival were made with historical controls, where patients who fulfilled the MET criteria were identified, however, the absence of MET service in place has been reported as the limitation of the study.

A descriptive exploratory study was conducted at a 578-beds government funded public health service, located in the Northern suburbs of Melbourne, Australia. ${ }^{14}$ A total of 178 patients were included in the study. Emergency department, medical and surgical wards were set as the study settings. The study found that nurses have the key position to recognise patients in the early stages of deterioration, and can provide care to these patients before they become critically ill and require activation of RRT. The study also found a clear relationship between abnormal physiological observations and adverse events. The retrospective nature of the data collection, and all inherent inabilities to capture any verbal but not documented reporting of physiological observations, have been reported as the limitations of the study.

The first National Institute for Health and Clinical Excellence (NICE) short clinical guideline was developed by NICE. ${ }^{2}$ The objective of the guideline was to provide a clinical guidance in recognising and responding to deteriorating patients. A pathway of ill 
patient was developed as the summary of the guideline. A detail explanation on the National Early Warning Score (NEWS), was given in the assessment part. The scoring table and cut off point of the tool have also been explained in detail in the guideline. The guideline was developed by experts from various fields of healthcare.

\section{DISCUSSION}

This current review provides an idea on the nurses' and junior doctors' knowledge in risk assessment, pharmacotherapy and their response towards deteriorating patients. This review also provides information on the signs and symptoms of deterioration as early as 48 hours prior to the adverse event. ${ }^{12}$ However, nurses and junior doctors tend to be unaware of these signs and symptoms. Moreover, this review also covered the data regarding the incidence of deteriorating patients, and the nurses' and junior doctors' knowledge in risk assessment of these patients. The results reported that nurses and junior doctors have a lack of knowledge in assessing the deteriorating patients.

\section{Risk assessment}

In the patients' assessment, it was found that nurses need to improve their clinical competencies, including in monitoring and adherence to reference protocols and documentation. ${ }^{4,6,15}$ Communications among healthcare providers also need to be improved. ${ }^{4}$ For junior doctors, the systematic review which focused on the junior doctors in the United Kingdom, has found that they were not fully prepared in terms of practice, especially in knowledge and skills. ${ }^{5}$ Nurses have been identified to play vital role in observing and monitoring patients, since patients' abnormal physiological findings were related to the adverse events that occurred, such as cardiac arrest. ${ }^{14}$

\section{Medication error}

In conjunction with the findings from the current review, it is also known that nurses have inadequate knowledge in assessing and recognising patients who were at risk of deterioration and require pharmacotherapy. Besides, the prescribing error has been found as the main contributor to the medication errors. ${ }^{10}$ The prescribing error was mainly done by doctors, as nurses were not allowed to prescribe medications. There was no significant difference in the rate of error between the newly qualified, junior, middle grade and senior doctors. ${ }^{10}$ Thus, inadequate knowledge in pharmacotherapy has led to medication errors by these nurses and doctors. For nurses, common medication errors occurred during administration and dilution of drugs.

\section{Rapid Response Team (RRT)}

This current review has also found that the emergency response team, such as MET, did help in reducing the mortality rate in hospitals. Mainly because cardiac arrest has been used as the indicator to determine deteriorating patients. Other than cardiac arrest, early warning sign tools, such as NEWS and MEWS were used to recognise deteriorating patients. Both tools have set the scores of three and above as the cut-off point for the nurses and doctors to initiate the RRT. Even though these tools were used infrequently, they are useful for inexperienced staffs. ${ }^{4}$ Multiple expertise, such as doctors, nurses, pharmacists, physiotherapists and dieticians, will work together in the RRT.

\section{Incidence of deteriorating patients}

Nurses and doctors are the pillars in providing healthcare to patients. Their skills and knowledge are essential in ensuring a quality care for patients, especially in making them feel safe and secure. ${ }^{16}$ They are the first responders for deteriorating patients in the general ward. ${ }^{17}$ Patients' conditions may deteriorate due to organ dysfunctions, comorbidities, history of organ failure and infections. $^{18}$

However, researchers have found that nurses and junior doctors are lacking in terms of knowledge in assessing the patients for deterioration in the general ward ${ }^{12,19}$, and have insufficient skills to respond to these patients. ${ }^{17}$ They were also found to not be fully prepared in recognising (risk assessment) and responding (providing treatment) to deteriorating patients. ${ }^{20}$

Deteriorating patients occur almost every day in the ward even though the nurses and doctors are present around them. Hospitalised patients often show declining vital signs up to 48 hours before deteriorating ${ }^{21}$, but delayed action has led these patients to a more serious condition. ${ }^{22.23}$ Therefore, risk assessment is important in ensuring the patients' lives and reducing the patients' admission rate to the Intensive Care Unit (ICU). ${ }^{24}$

Failure to recognise the early signs of deterioration has been a global concern. Recognising a deteriorating patient is an essential nursing skill, however, the structured framework should be in place, in order to have an effective patient assessment $^{25}$ by making observations crucial. ${ }^{26}$ However, ineffective observation may hinder the timely recognition of clinical deterioration, leading to subsequent adverse events occurring in the general ward, i.e. mortality, unplanned ICU admissions and cardiopulmonary arrests, which made assessing the patient's safety very important. ${ }^{27}$ 
Skills and knowledge of nurses and junior doctors had been recognised as one of the factors contributing to the failure of recognising and responding appropriately to the clinical deteriorations. ${ }^{5}$ Doctors and nurses who failed to stabilise the patients, which include securing the airway, breathing and circulation, will negatively impact the patient's health status. ${ }^{28}$ Therefore, collaboration among nurses and junior doctors were said to be crucial, in producing a better quality care and to minimise deterioration risks among patients in the ward.

According to study, $60 \%$ of cardiac arrest, hospital death and unexpected admission to the ICU were detected by common physiological changes, i.e. hypotension, and fall within the Glasgow Coma Score (GCS). ${ }^{29}$ Still, due to the lack of knowledge and skills in responding to clinically ill patients, nurses and junior doctors tend to risk the patient's life.

In addition, serious incidents that were reported to the National Patient Safety Agency (NPSA) identified that $11 \%$ of the deaths were due to patient deterioration not being appropriately recognised or acted upon. ${ }^{19}$ In the recent years, awareness of patients managed in the general ward has been increased, whilst access to the critical care beds has been decreased.

Effective observation on ward patients is the first key step in identifying deteriorating patients and effectively managing their care. Better understanding on the nurses' observation practice is vital, in order to attain a positive impact on the patient outcomes by preventing deterioration that can lead to critical illness, ICU admission, and/or death.

\section{Nurses' and junior doctors' knowledge in assessing deteriorating patients}

According to McIntosh, a nurse is defined as a person who cares for an ill or injured person. ${ }^{23}$ This study specifically focused on the hospital setting. During hospitalisation, medical team will closely monitor patients' condition. The medical team consists of nurses, doctors and other allied health care providers. Nurses have been thought to play the core role in patients' care, as nurses are responsible for conducting observations on vital signs, and monitoring patients' progress during hospitalisation.

Nurses often recognised deteriorating patients through their intuitions, rather than using the measurement of vital signs. ${ }^{7}$ Intuition is defined as a judgment without rationale, a direct apprehension and response without recourse to consider rationality. ${ }^{30} \mathrm{~A}$ vital sign is an objective fact that is gathered from patients' current condition. A combination of both objective and subjective facts from patients' data, will provide a complete understanding towards patient's condition. ${ }^{31}$

Nurses play an important role in ensuring patients' safety, responsible for staying with them throughout the day, and are expected to monitor their conditions. However, there is an evidence which indicates that most nurses are not always clear about when to call for assistance, or sometimes do not seek for advice and fail to appreciate clinical urgency. ${ }^{12,30}$ Observing or measuring vital signs are the first step in monitoring patient's condition.

However, taking observations is increasingly seen as a task-based activity, rather than for gathering information. ${ }^{32}$ This situation may lead to endangering patients' safety, where early actions and responses are needed in the initial identification of deterioration. Effective leadership from nurses with senior roles is needed, since there is a possibility that patients' observations were not being taken as a serious responsibility.

Patients' observations should be formed as a part of the nurses' core skill set, in order to provide the best actions for patients who are at risk of deterioration. The taking and recording of observations should be seen as pieces of a clinical jigsaw puzzle, to show how the patients are progressing and potential areas of concern. Observations that are often perceived as basic and routine, are in fact the vital parts of the information gained, so as to ensure a safer patient care and early recognition of deterioration. ${ }^{32}$

Respiratory monitoring has always been neglected and considered unimportant. Nowadays, some nurses also neglect manual blood pressure monitoring, since they heavily relied on the use of automatic blood pressure monitoring machine. This has also been the reason why sometimes respiratory monitoring was neglected, since the machine was unable to provide respiration reading. ${ }^{33} \mathrm{~A}$ study found that $85 \%$ of the respondents stated that they used the electronic observation device in their working areas, and $42 \%$ were confident that nurses were less likely to identify the signs of deterioration in patients when electronic observation devices were used. ${ }^{34}$

Conventional ways of observation include the usage of sphygmomanometer to manually measure blood pressure, and manual pulse reading to monitor respiratory rate. However, these practices are rarely used nowadays. Electronic observations through recordings have been increased; however, they are still aware that manual blood pressure measurements provide a more accurate result. ${ }^{34}$

The issue that nurses abandon the respiratory rate monitoring was not only due to the reliance on technology for patient assessments alone, but it is more complicated than that. ${ }^{33}$ Concerns were raised 
regarding how respiratory rate monitoring have been underestimated, and nurses' understanding towards the physiological basis of this indicator.

Nurses' experiences are crucial in making a judgment regarding the necessity to perform the assessment of vital signs. ${ }^{33}$ Nevertheless, the impact of technology on nursing practices should not be overlooked, and critiques on its contribution to effective patient assessment are warranted, especially against the recent attention on the concerns over 'missed' patient care. ${ }^{35}$

Other than nurses, junior doctors also play an important role in ensuring patients' safety and positive recovery. Previous research suggested that the care of acutely unwell patients is an area in which many medical graduates feel that they were poorly prepared..$^{36-40}$ Junior doctors have been exposed to deteriorating patients since their study period, however, the hands-on experience was not enough. ${ }^{41}$

The unpreparedness of junior doctors in providing treatments to deteriorating patients has been alarming. A study revealed that junior physicians are lacking in knowledge, confidence and competent skills, in all aspects of acute care, including the basic task of recognition and management of the acutely ill patients. ${ }^{20}$ In addition, junior doctors' skills in physical examinations have been declining, due to the lack of opportunity to improve these skills. ${ }^{41}$

There were some data that showed the junior doctors' skills in the physical examinations were declining due to the high dependency and reliance on the technologies, such as in the imaging technology. ${ }^{42}$ Although investigation technologies are more accurate, overusing them may reduce the doctors' skills. ${ }^{43}$ Junior doctors often omit central nervous system (CNS) during physical examinations, which caused incomplete data obtained when assessing the patient's conditions. ${ }^{42}$

Acutely unwell patients often require empirical resuscitative measures to be initiated concurrently with the investigations, which aimed to characterise the nature of the illness and ultimately reach a definitive diagnosis. ${ }^{44}$ However, once they came up with a diagnosis, they often found themselves fixated on the illness, even when the findings from additional examinations were inconsistent with their initial hypothesis. ${ }^{44}$

\section{CONCLUSION}

Recognition and management of deteriorating patients in the general ward involved complex and challenging tasks for nurses and junior doctors. Good knowledge in risk assessment provides a major difference and positive impact on patient care. Their knowledge in risk assessment should be benchmarked on their actions in responding to deteriorating patients. This current review showed that it is important to evaluate nurses' and junior doctors' knowledge, attitudes and practices in recognising and responding to deteriorating patients. This is because an effective recognisation and response towards patients at risk of deteriorating may produce better outcome in patients' treatment. It is also important to identify nurses' and junior doctors' knowledge in pharmacotherapy, as medication error, e.g. prescribing error can be easily prevented. Even though nurses do not have the right to prescribe medication, with their knowledge, they can recognise error before medication is administrated to patients.

\section{ACKNOWLEDGEMENT}

This review is part of a bigger study conducted with the support of funding from IIUM Research grant ( EDW B: 14-112-0997) awarded to the lead author. The authors would like to thank the university for the grant.

\section{REFERENCES}

1. Bright $\mathrm{D}$, Walker $\mathrm{W}$, Bion J. Clinical review: Outreach- a strategy for improving the care of the acutely ill hospitalize $d$ patient. Crit Care 2003; 8:33-40.

2. National Institute for Health and Clinical Excellence (NICE). Acute illness in adults in hospital: Recognising and responding to deterioration. Manchester: National Institute for Health and Clinical Excellence 2007.

3. McQuillan P, Pilkington S, Allan A, Taylor B, Short A, Morgan G, Smith G. Confidential inquiry into quality of care before admission to intensive care. BMJ 1998; 316:1853-8.

4. Donohue LA, Endacott R. Track, trigger and teamwork: Communication of deterioration in acute medical and surgical wards. Intens Crit Care Nurs 2010; 26:10-7.

5. Cameron A, Millar J, Szmidt N, Hanlon K, Cleland J. Can new doctors be prepared for practice? A review. Clin Teach 2014; 188-92.

6. Cooper S, Cant R, Porter J, Missen K, Sparkes L, McConnell-Henry T, Endacott R. Managing patient deterioration: assessing teamwork and individual performance. Emerg Med J 2013; 377 381.

7. Odell M. Detection and management of the deteriorating ward patient: an evaluation of nursing practice. J Clin Nurs 2014; 24:173-82.

8. Hsaio G Y, Chen IJ, Yu S, Wei IL, Fang YY, Tang FI. Nurses' knowledge of high-alert medications: instrument development and validation. J Adv Nurs 2009; 66:177-90.

9. Bergqvist $M$, Karlsson EA, Bjorksten KS, Ulfvarson J. Medication errors by nurses in Sweden-Classification and contributing factors. Open Access Scientific Reports 2012; 1:1-5.

10. Seden K, Kirkham JJ, Kennedy T, Lloyd M, 
James S, Mcmanus A, Khoo S. Cross-sectional study of prescribing errors in patients admitted to nine hospitals across North West England. BMJ Open 2013; 3:e002036.

11. Franklin BD, Reynolds M, Shebl NA, Burnett S, Jacklin A. Prescribing errors in hospital inpatients: a three-centre study of their prevalence, types and causes. Postgrad Med J 2011; 87: 739-45.

12. Ludikhuize J, Smorenburg SM, de Rooij SE, de Jonge $E$. Identification of deteriorating patients on general wards; measurement of vital parameters and potential effectiveness of the Modified Early Warning Score. J Crit Care 2012; 27:424-e7.

13. Konrad D, Jaderling $G$, Bell $M$, Granath $F$, Ekbom A, Martling CR. Reducing in-hospital cardiac arrests and hospital mortality by introducing a medical emergency team. Intensive Care Med 2010; 36:100-6.

14. Considine J, Currey J. Ensuring a proactive, evidence-based, patient safety approach to patient assessment. J Clin Nurs 2014;2 4: 300-7.

15. Odell $M$, Victor $C$, Oliver D. Nurses' role in detecting deterioration in ward patient: Systematic literature review. J Adv Nurs 2009; 65:1992-2006.

16. Kvale K, Bondevik M. Patients' perceptions of the importance of nurses' knowledge about cancer and its treatment for quality nursing care. Oncol Nurs Forum 2010; 34:436-42.

17. Sheng CK, Zakaria MI, Rahman NH, Jaalam K, Adnan WA. Cardiopulmonary resuscitation: The short coming in Malaysia. Malays J Med Sci 2008; 15:49-51.

18. Tsai JC, Cheng CW, Weng SJ, Huang CY, Yen $\mathrm{DH}$, Chen HL. Comparison of risks factors for unplanned ICU transfer after ED admission in patients with infections and those without infections. Sci World J 2014.

19. Thomson R, Luettel D, Healey F, Scobie S, Beaumont K. The fifth report from the Patient Safety Observatory. Safer care for the acutely ill patient: learning from serious incidents. London: National Patient Safety Agency 2007.

20. Smith CM, Perkins GD, Bullock I, Bion JF. Undergraduate training in the care of the acutely ill patient: a literature review. Intensive Care Med 2007; 33:901-7.

21. Simmes F, Schoonhoven L, Mintjes J, Fikkers BG, van der Hoeven JG. Incidence of cardiac arrest and unexpected death in surgical patients before and after implementation of a rapid response system. Ann Intensive Care 2012; 2:20.

22. Carberry M, Headley E. How helpful are early warning scores? Nurs Times 2014; 110:12-4.

23. McIntosh C. Cambridge Advanced Learner's Dictionary Fourth Edition. Cambridge: Cambridge University Press 2013.

24. Jones D, Lippert A, DeVita M, Hillman K. What's new with rapid response systems? Intensive Care Med 2015; 41:315-7.
25. Clarke C. Promoting the $6 \mathrm{Cs}$ of nursing in patient assessment. Nurs Stand 2014; 28:52.

26. Mok WQ, Wang W, Liaw SY. Vital signs monitoring to detect patient deterioration: An integrative literature review. Int J Nurs Pract 2015; 21: 91-8

27. Rose L, Clerk S. Vital signs. Am J Nurs 2010; 11095:11.

28. Frost PJ, Wise MP. Early management of acutely ill ward patients. BMJ 2012; 345:e5677.

29. Kause J, Smith G, Prytherch D, Parr M, Flabouris A, Hillman K. A comparison of antecedents to cardiac arrest, death and emergency intensive care admission in Australia and New Zealand, and the United Kingdom- the ACADEMIA study. Resuscitation 2004; 62:275-82.

30. Benner P, Tanner C, Chesla C. Expertise in nursing practice: caring, clinical judgement and ethics. New York: Springer 2009.

31. Gao H, McDonnell A, Harrison D, Moore T, Adam $\mathrm{S}$, Daly K. Systematic review and evaluation of physiological track and trigger warning system for identifying at-risk patients on the ward. Intensive Care Med 2007; 33:667-9.

32. Boulanger C, Toghill M. How to measure and record vital signs to ensure detection of deteriorating patients. Nurs Times 2009; 105:102.

33. Ansell H, Meyer A, Thompson S. Why don't nurses consistently take patient respiratory rates? Br J Nurs 2014; 23: 414-18.

34. Kisiel M, Perkins $C$. Nursing observations: Knowledge to help prevent critical illness. $\mathrm{Br} \mathrm{J}$ Nurs 2006; 15:1052-6.

35. Blackman I, Henderson J, Willis E, Hamilton P, Toffoli L, Verrall C, Abery E, Harvey C. Factors influencing why nursing care is missed. J Clin Nurs 2015; 24:47-56.

36. Gome JJ, Paltridge D, Inder WJ. Review of intern preparedness and education experiences in general medicine. Internal Medicine Journal 2008; 38:249-53.

37. Illing J, Morrow G, Kergon C, Peile E, Davies C, Baldauf B, Allen M, Johnson N, Morrison J. How prepared are medical graduates to begin practice? A comparison of three diverse UK medical schools. London: General Medical Council Education Committee 2008.

38. Lueddeke GR, Anderson FH, Carr NJ, Mitchell BS, Taylor MS. Looking 'back to the future': alumni perceptions of a UK undergraduate medical programme. Medical Teacher 2006; 28:654-56.

39. Wall D, Bolshaw A, Carolan J. From undergraduate medical education to preregistration house officer year: how prepared are students? Medical Teacher 2006; 28:435-9.

40. Berridge EJ, Freeth D, Sharpe J, Roberts CM. Bridging the gap: supporting the transition from medical student to practising doctor - a 2-week preparation programme after graduation. Medical Teacher 2007; 29:119-27.

41. Sheehan D, Wilkinson TJ, Billett S. Interns' participation and learning in clinical 
environments in New Zealand hospital. Academic Medicine 2005; 80:302-8.

42. Oliver CM, Hunter SA, Ikeda T, Galletly DC. Junior doctor skill in the art of physical examination: a retrospective study of the medical admission note over four decades. BMJ Open 2013; 3: e002257.

43. Tavel M. Cardiac auscultation: a glorious past-but does it have a future? Circulation 1996; 93:1250-3.

44. Tallentire VR, Smith SE, Skinner J, Cameron HS. Understanding the behaviour of newly qualified doctors in acute care contexts. Medical Education 2011; 45:995-1005. 